DOI https://doi.org/10.18551/rjoas.2017-01.33

\title{
EFFICIENCY ANALYSIS OF MEAT PROCESSING INDUSTRY IN INDONESIA
}

\author{
Jafrizal, Robiani Bernadette, Suhel \\ Faculty of Economics, University of Sriwijaya, Palembang, Indonesia \\ E-mail: drh jafrizal@yahoo.co.id, robiani64@yahoo.com, suhel feunsri@yahoo.co.id
}

\begin{abstract}
This paper aims to analyze the efficiency of the meat processing industry in Indonesia largescale and medium-year period 1990-2013. The method used data envelopment analysis (DEA) model of Variable Return to Scale (VRS) Input-oriented. It was found that, the estimation value Constant Return to Scale (CRS) model of efficiency with an average of 89.38 percent, which means that the industry is only able to optimize the resources available inputs to produce a production of 89.38 per cent, in other words there is still potential inputs that they can be optimized for 10.62 percent assuming all companies operating at an optimal scale. VRS model results by an average of 95.7 percent, which means that the efficiency is still below 100, there are inefficiencies at 4.3 percent, assuming the company is not operating at optimal scale due to factors existing constraints, medium scale efficiency (Scale) an average of 93.36 per cent less than 100 percent means that the industry is on a scale of inefficiency. The implications of negative growth efficiency or below 100 percent is the need for skills development of workers in order to adapt to technological upgrading and make the selection of efficient combination of inputs.
\end{abstract}

\section{KEY WORDS}

Efficiency, data envelopment analysis, variable return to scale, meat processing industry.

«It was inevitable that the future is in the processing industry,» this is what the statement C.P. Timmer, researcher of the Center for Development Globel can ever Star Services for research on food security in Indonesia. Processing industry plays an important role in the nation's economy, including the meat processing industry. Meat processing industry is one of the food industry which contributes greatly to the economy (Lambert, 1994; Ali, 2007; Knudson, et al., 2010; Ali and Pappa, 2011).

According to BPS data (2015), the contribution to Gross Domestic Product of the meat processing industry each year has increased from 8.72 percent in 2007 to 56 percent in 2012 , a share which is the 2 nd highest of the food and beverage industry. The increase was not followed by the growth rate of the Gross Domestic Product of the industry continues to decline from 12.17 percent in 2007 to 1.13 percent in 2012. Growth in industrial processing and preserving of meat in Indonesia from 1985 to 2013 year average growth of about 26.6 per cent per year, the average workforce grew 8 percent and corporate units grew modestly around an average of 4 percent.

Problems of growth efficiency of the processing industry in Indonesia has become a concern among researchers in recent decades (see: Aswicahyono, 1998; Basri, 2001; Margono and Sharma, 2006; Modjo, 2007; Probowo and Cabanda 2011; Setiawan, 2013; and Surjaningsih and Permono, 2014). When the competition is going low, it will cause producers to operate inefficiently so that loss of efficiency and productivity (Gopinath, et al., 2002; Nurdianto, 2004).

Changes efficiency contributes to productivity growth as reported Saputra (2011), that in the period 1990-2001 subsector processing industry in general has high efficiency. Bappenas (2010) find the positive growth of technical efficiency, productivity growth in the processing industry the period 2000-2007. The same was reported Probowo and Cabanda (2011), in the period 2000-2005 the processing industry in Indonesia is experiencing technical inefficiency.

Various research efficiency of meat processing industrial has also been carried out in various countries with different results, such as, among others, by Xia and Buccola (2002), 
which conducts research in the United States, found that the level of productivity of the meat processing industry decreased. Ali (2007) conducted a study in India found that in the period from 1980 to 2003 occurred inefficient use of capital and labor inputs and the low productivity growth. Nossal et al., (2008) conducted a study in Australia, found that the productivity of beef processing industry is increasing every year, driven by a combination of a moderate expansion of output and a decline in the use of multiple inputs.

Research is also being done in Europe, including in Ukraine, Goncharuk (2009) found increased growth of efficiency resulting from the reduction in the use of capital input, labor input. Keramidou et al., (2011) reported the results of his research on the meat processing industry in the period 1994-2007 Greece, find growth is inefficient use of capital and labor inputs. In Spain, Kapelko, et al., (2012) found that a decline in productivity driven by technical setbacks, despite the growth in technical efficiency and scale efficiency.

In connection with differences on the above results, this study will analyze the efficiency of the meat processing industry in Indonesia on period 1990-2013.

Theories efficiency first appeared in 1957, was Farrell with microeconomic study approach. In particular, Farrell (1957) describe new insights into two important things: how to define efficiency and how to calculate a measure of efficiency. In the approach to Farrell, the measurement of economic efficiency associated with use of frontier production function, contrary to the notion underlying performance largely econometric literature on production functions.

Farrell (1957) divides the efficiency of the company into two components, namely the technical efficiency and allocative efficiency. The two measures are then combined into economic efficiency (economic efficiency). Sengupta (1995) and Coelli, et al., (2005) divides efficiency into three components, namely allocative efficiency (AE), economic efficiency (EE) and technical efficiency (TE).

Allocative efficiency (AE) reflects the company's ability to optimize the use of inputs in optimal proportions given their respective prices and production technology. Economic efficiency (EE) is defined as the ability of a company to produce the quantity of output that has been determined by the minimum cost for a certain technological level. A company can be said to be economically efficient if the company can minimize the cost of production to produce a specific output with a level of technology that is commonly used as well as the prevailing market price. Technical efficiency is a measure of the company's success in producing a maximum output of the set of inputs available (Sengupta, 1995).

Efficiency can be estimated with parametric or nonparametric methods. The preferred method of estimation has become an issue of debate, with some researchers prefer nonparametric approach (Seiford and Thrall, 1990) and some researchers use a parametric approach. Parametric measurements including determining and estimating the stochastic frontier production or cost stochastic frontier in this method, the output (or cost) is assumed to be a function of the input (or output), inefficiency and random error. On the other hand, parametric frontier functions require the definition of a particular functional form for technology and for the inefficiency error term. Terms of the functional form causing the problem specification and estimation (Sengupta, 1987). Measurement of technical efficiency tends to be limited to technical and operational influence in the process of converting inputs into outputs. As a result, efforts to improve the technical efficiency requires only micro policy which is internal, namely the control and optimal resource allocation. In the economical efficiency, the price can not be considered given, because prices can be affected by macro policy.

Calculation of efficiency according to the Coelli Farrel, et al. (2005); Cesaro, et al., (2009), there are two approaches, with the approach of input and ouput approach. First, the input approach, we set a target output by selecting the input to a minimum. Input orientation emphasizes the question of how much the number of inputs can be reduced (reducing input) proportionally without changing the quantity of output produced. Second, the output approach to see how big an increase in the number of output without increasing the amount of use input. Orientation output emphasis on the question how much output can be increased (output expanding) proportionally without changing the number of inputs used. 
According Coelli, et al., (2005), the output approach there are three types of additional output that constant return to scale, decreasing returns to scale, and increasing returns to scale. For input and output approach will provide similar technical efficiency calculations in the constant return to scale, but show different results in decreasing / increasing returns to scale. Efficiencies generated through the output approach indicates the amount of output can be increased without additional input.

Data Envelopment Analysis (DEA) is a mathematical program optimization method that measures the technical efficiency of a company and compares relative to other companies. DEA was originally developed by Farrell (1957), which measures the technical efficiency one input and one output, into a multi-input and multi-output, using a framework of values relative efficiency as a ratio of input (single virtual input) to output (single virtual output) (Giuffrida \& Gravelle, 2001). Initially, DEA popularized by Charnes, et al., (1978) by the method of constant returns to scale (CRS) and developed by Banker et al., (1984) for variable returns to scale (VRS), which eventually famous models CCR and BCC.

The main advantage of DEA is easy to use by combining multiple inputs and outputs to calculate technical efficiency. DEA models can generate new alternatives to improve performance compared to other techniques. Linear programming is the backbone of DEA methodology that is based on the optimization platform. DEA is different from other methods in identifying ways of optimal average performance.

\section{METHODOLOGY OF RESEARCH}

The Scope of Research. The scope of this study industrial processing and preservation of meat in Indonesia large scale and are using the categories Classification of Indonesian Business Field (KLUI) 1990 with code 31 112, Standard Industrial Classification of Indonesia (ISIC) 1998, 2000, 2005 with the code 15112 and ISIC 2009 with 10130 code.

Types and Sources of Data. The data used in this research is time series data processing and preservation of meat industry in Indonesia are derived from the annual survey data Large and Medium Manufacturing Statistics Indonesia-year period 1990-2013 were not published. Chosen in 1990 as in 1990 the state of Indonesia first began importing cattle that became the beginning of the meat processing industry uses imported beef. Chosen in 2013 as the last year's research data due consideration of the availability of annual survey data for 2013 BPS only available in May 2015.

Data used in the study includes data input and output as well as the value of imports. Input and output variables are used, among other things: The cost of raw and auxiliary materials (raw materials); Spending on labor; Electric power purchased by the industry; Spending fuels and lubricants industries; Other expenses consist of cost of capital lease; The output value is the output value of the meat processing industry

Analysis method. The model was developed by Banker, Charnes, and Cooper (model BCC) in 1984 and is a development of the model CCR. This model assumes that the company is not yet operating at optimal scale. The assumption of this model is that the ratio between the input and output additions are not the same (variable returns to scale). That is, the addition of $x$ times the input will not cause output increased by $x$ times, can be smaller or larger than $x$ times. Banker, Charnes and Cooper (1984) have extended measurement DEA method for the case of variable returns to scale (VRS). This model distinguishes between pure technical efficiency and scale efficiency (SE), identify whether increasing, decreasing or constant returns to scale are found. As a result, assuming a linear CRS should change by adding a further convexity constraint $N 1{ }^{\prime} \Lambda=1$, therefore, form-oriented VRS DEA model inputs specified as:

$$
\begin{aligned}
& \text { TE vrs } \Theta, \Lambda=\min \Theta \\
& \text { st }-y i+Y \Lambda \geq 0 \\
& \Theta x i-X \lambda \geq 0 \\
& N^{\prime} \lambda=1 \lambda \geq 0
\end{aligned}
$$


where $\mathrm{N} 1$ is an $\mathrm{N} \times 1$ vector of satu. $\theta$ is the input value of technical efficiency under VRS, has a value of $0 \leq \theta \leq 1$. As in the previous case, if the value of $\theta$ is equal to one, the company was on the frontier, while $\lambda$ vector is $N \times 1$ vector of weights that define a linear combination of the company's enterprise-i.Karena to VRS DEA model is more flexible and enveloping data in a way that is more stringent than the CRS DEA model, the value of the VRS technical efficiency is equal to or greater than the value of CRS technical efficiency, This influence can be used to measure the scale of business efficiency:

$$
S E=T E C R S / T E \text { VRS }
$$

SE $=1$ means the scale of efficiency or SE $<1$ indicates scale inefficiency that could be caused by increasing or decreasing returns to scale. As a result, some of the VRS units that can efficiently be inefficient under the scheme CRS because the size deviates from the optimum scale. The weakness in this procedure is that it can give an indication whether the company operates under increasing or decreasing returns to scale. This can be determined by calculating the equation additional DEA - increasing returns to scale (NIRS). Model VRS DEA previously can be changed by changing the boundaries $N 1{ }^{\prime} \lambda=1$ with $N 1^{\prime} \lambda \leq 1$ and other surfaces that will be able to distinguish between the different scales in the structure of production. In particular:

- $\quad$ if TEnirs $=$ TEvrs $\neq$ TEcrs the units producing in decreasing return to scale;

- if TEnirs $\neq$ TEvrs = TEcrs the units producing in increasing returns to scale;

- if TEnirs $=$ TEvrs $=$ TEcrs the production unit at constant return to scale.

\section{RESULTS AND DISCUSSIONS}

The efficiency value of this research is the value obtained from the technical efficiency estimation using Data Envelopment Analysis method -Variable Return to Scale (DEA-VRS) input oriented. Table 4.1 of the visible results of DEA-VRS input oriented that the overall value of the average efficiency of industrial processing and preservation of meat in Indonesia period 1990-2013 CRS model with an average of 89.38 percent, which means that the industry is only able to optimize resource input available to generate production by 89.38 percent in other words, there is still potential inputs that they can be optimized by 10.62 percent, assuming all companies operating at an optimal scale. VRS model results by an average of 95.7 percent, which means that the efficiency is still below 100, there are inefficiencies at 4.3 percent, assuming the company is not operating at optimal scale due to factors existing constraints, medium scale efficiency (Scale) an average of 93.36 per cent less than 100 percent means that the industry is on a scale of inefficiency. The implications of negative growth efficiency or below 100 percent is the need for skills development of workers in order to adapt to technological upgrading.

From Table 1 also shows that the minimum value interval efficiency value VRS models of 85.4 percent and a maximum value of 100 percent, with a standard deviation of 4 percent which means that there are differences in sample value to the value of the average of 4 percent during the study period. The estimation results of the efficiency as follows: Under the conditions of return to scale industries during the study period of 1990-2013, there are 18 units of the company each year during the study period conditions return to scale is at $\lambda>1$ means that the degree of change in output as a result of changes in input called the degree of acquisition ascending (increasing returns to scale). This condition can occur due to the increased scale of operations, occurs due to specialization of tasks and functions, as well as the use of special machines that are more productive and related to the liberalization policy in the industry especially in 1986 whose effects are still felt the time until the moment before the economic crisis of 1997 / 1998. The number of technology and innovation as well as investment and the stable economic conditions contributed to the growth of the industry not to mention the meat processing industry. 
Table 1 - Values Efficiency and Preserving Meat Processing Industry for the Period of 1990-2013*

\begin{tabular}{|c|c|c|c|c|c|c|}
\hline \multirow{2}{*}{ Period } & \multicolumn{3}{|c|}{ Efficiency (percent) } & \multirow{2}{*}{$\begin{array}{l}\text { IRS } \\
\text { (Unit) }\end{array}$} & \multirow{2}{*}{$\begin{array}{l}\text { CRS } \\
\text { (Unit) }\end{array}$} & \multirow{2}{*}{$\begin{array}{l}\text { DRS } \\
\text { (Unit) }\end{array}$} \\
\hline & CRS & VRS & Scale & & & \\
\hline $1990-1992$ & 85,07 & 90,81 & 93,68 & 18 & 0 & 0 \\
\hline 1993-1995 & 98,72 & 99,71 & 99,01 & 23 & 0 & 1 \\
\hline 1996-1998 & 94,08 & 99,06 & 94,97 & 21 & 0 & 2 \\
\hline 1999-2001 & 86,04 & 96,37 & 89,28 & 18 & 2 & 3 \\
\hline 2002-2004 & 85,6 & 93,72 & 91,34 & 13 & 1 & 5 \\
\hline $2005-2007$ & 89,7 & 97,06 & 92,42 & 21 & 2 & 5 \\
\hline 2008-2010 & 90,52 & 96,21 & 94,09 & 21 & 1 & 7 \\
\hline 2011-2013 & 85,29 & 92,61 & 92,1 & 12 & 3 & 14 \\
\hline Average & 89,38 & 95,7 & 93,36 & 18 & 1 & 5 \\
\hline Std. Dev & & 4,0 & & & & \\
\hline Minimum & & 85,4 & & & & \\
\hline Maximum & & 100,0 & & & & \\
\hline \multicolumn{2}{|c|}{$\begin{array}{l}\text { Scale }=\text { Scale Efficiency }=\text { crs } / \text { vrs } \\
\text { CRS }=\text { Constant Return to Scale } \\
\text { VRS }=\text { Variable Return to Scale }\end{array}$} & \multicolumn{3}{|c|}{$\begin{array}{l}\text { IRS = Increasing Return to Scale } \\
\text { DRS = Decreasing Return to Scale } \\
\text { Tech = Technology }\end{array}$} & & \\
\hline
\end{tabular}

From the above results it appears that a drop in efficiency from the period 1993-1995 amounted to 99.71 per cent to 92.61 per cent in 2011-2013 peridoe. The condition is the same as the results of technical efficiency of food processing industries in Indonesia are conveyed by Margono and Sharma (2006) in the period from 1993 to 2000, and Ikhsan (2007) in the period 1988-2000, which found that the level of efficiency in the food processing industry Indonesia has decreased.

Periodically, in the period of 1990-1992 the average efficiency of 85.07 percent CRS models, meaning that there is still potential to improve efficiency by optimizing the use of inputs in the industry amounted to 14.93 percent, assuming all companies operating at an optimal scale. VRS model of efficiency average of 90.81 percent, meaning that it is still possible for the company or the industry to further increase its technical efficiency by reducing the level of technical inefficiency in the use of inputs by reducing the use of raw material inputs and fuel, electricity and other expenses that occur excessive use of 9.19 per cent, assuming the company is not operating at optimal scale due to factors constraints. Overall the 1990-1992 period were on a scale of inefficiency because efisiensirata scale value by an average of 93.68 percent, still below 100 percent. This condition may occur related to the liberalization policy in the industry especially in 1986 whose effects are still felt the time until just before the financial crisis. The number of technology and innovation and investment that support the industry at that time have not been fully utilized by the meat processing industry. The low labor skills possessed in using technology. This is consistent with reports Priyanto (2005), the condition of the period 1990-2000 is the implementation of policy finance minister in 1989 that lowered import tariffs on beef. This condition, in which industrial processing and preservation of meat that began using imported meat as raw materials benefited from the imposition of import tariffs on meat decreased from 40 percent in 1989 down to 5 percent in 2000. At the time of the imposition of high import tariffs in 1989 to 40 percent, it also affected the price of imported meat but the meat processing industry is still largely domestic beef used as a raw material. Along with a reduction in tariffs and the price of imported meat imports have also increased the composition of meat used as a raw material. It contributed to the establishment of conditions that efficient in terms of cost on industrial processing and preservation of meat in Indonesia.

In the period 1993-1995 the average efficiency of 98.72 percent CRS models, meaning that there is still potential to improve efficiency by optimizing the use of inputs in the industry by 1.28 percent with the assumption that all companies operating at an optimal scale. VRS model of efficiency average of 99.71 percent, meaning that there is still potential to improve 
efficiency by optimizing the use of inputs by 0.29 per cent, assuming the company is not operating at optimal scale due to factors constraints. Overall the 1993-1995 period were on a scale of inefficiency because of the value scale of an average efficiency of 99 percent, is still below 100 percent. Conditions return to scale is at $\lambda>1$ means that the degree of change in output as a result of changes in input called the degree of acquisition ascending (increasing returns to scale).

In the period 1993-1995 there was an increase of efficiency when compared to the previous period but still not efficient. The condition can occur due to the processing of the meat processing industry going technology development and orientation of higher capital compared with other food industry, so that the meat processing industry has increased the efficiency of the previous period. This condition is consistent with the reports Tanuwijaya and Sharma (2004) Aswicayono and Hill (2002), reported that productivity growth in the food processing industry that is driven by the positive contribution of the growth efficiency. Modjo (2006) reported that the productivity of the industry declined in the period from 1990 to 1995 but there has been growth in efficiency. In the period 1990-1995 the initial process of learning by doing in adopting the technology because the company is not operating at full production capacity. This production growth is a positive contribution of the growth of efficiency changes.

In the period 1996-1998 the average efficiency of 94.08 percent CRS models, meaning that there is still potential to improve efficiency by optimizing the use of inputs in the industry at 5.92 percent with the assumption that all companies operating at an optimal scale. VRS model of efficiency average of 99.06 percent, meaning that there is still potential to improve efficiency by optimizing the use of inputs by 0.94 percent, assuming the company is not operating at optimal scale due to factors constraints. Overall the period 1996-1998 were on a scale of inefficiency due to efficiencies of scale value by an average of 94.97 percent, still below 100 percent. Conditions return to scale is at $\lambda>1$ means that the degree of change in output as a result of changes in input called the degree of acquisition ascending (increasing returns to scale). These results are consistent with the results of Klein and Luu (2003) provide evidence of the influence of political factors with negative technical efficiency during the crisis of 1997-1998, and only after a positive growth in 1999. Bappenas (2010) also reported that the Indonesian processing industry in the period the period 1997/1998 inefficiency, as seen in the growth of productivity is lower than the period before the 1998 crisis.

Conditions in the period $1996-1998$ as a result of rising prices of industrial raw materials due to inflation, but the effect on the efficiency is only down slightly from the period 1994-1996. Many companies are not operational during this period due to rising production costs and declining consumer purchasing power. Companies that can efficiently use a competitive advantage in lowering production costs to maximize utilization of its available resources. Companies that use imported inputs will bear a bigger impact on the rising cost of imported raw materials, which in turn will lower the efficiency.

In the period 1999-2001 the average efficiency of 86.04 percent CRS models, meaning that there is still potential to improve efficiency by optimizing the use of inputs in the industry amounted to 13.98 percent, assuming all companies operating at an optimal scale. VRS model of efficiency average of 96.37 percent, meaning that there is still potential to improve efficiency by optimizing the use of inputs by 3.63 per cent, assuming the company is not operating at optimal scale due to factors constraints. Overall the 1999-2001 period were on a scale of inefficiency due to efficiencies of scale value by an average of 89.28 percent, still below 100 percent. Toscale return conditions are at $\lambda>1$ means that the degree of change in output as a result of changes in input called the degree of acquisition ascending (increasing returns to scale).

In the period of 1999-2001 is still a drop in efficiency compared to the previous period when the crisis of 1997-1998. This can happen still allegedly associated with the process of consolidation of economic policy following the crisis of 1998 and the instability of economic conditions. These results differ from the findings of Klein and Luu (2003), Margono and Sharma (2004), Modjo (2007) and Setiawan (2013) who found that after a period of crisis in 
$1997 / 1998$ the food processing industry (meat) experienced positive growth efficiency. Differences in results can be caused because the industry is still able to take advantage of its resources efficiently, despite an unstable condition after the domestic political situation, high interest rates and the exchange rate access to financial resources is still low, as well as the practices and values managerial relatively not professional. The low value of the rupiah resulted only in capital input but although expensive raw material procurement can still be obtained, so that the industry can still increase productivity with the use of technological equipment and resources to the optimum.

In the period 2002-2004 the average efficiency of 85.6 percent CRS models, meaning that there is still potential to improve efficiency by optimizing the use of inputs in the industry amounted to 14.4 percent, assuming all companies operating at an optimal scale. VRS model of efficiency average of 93.72 percent, meaning that there is still potential to improve efficiency by optimizing the use of inputs by 6.28 percent, assuming the company is not operating at optimal scale due to factors constraints. Overall the 2002-2004 period are inefficiency due to efficiencies of scale value by an average of 91.34 percent, still below 100 percent. Conditions return to scale is at $\lambda>1$ means that the degree of change in output as a result of changes in input called the degree of acquisition ascending (increasing returns to scale). The period 2002-2004 was a trend decline in efficiency compared to the previous period. This condition is similar to that found by Robiani (2008), Setiawan (2013), Ndari and Permono (2014), reported that the growth occurred in the period 2000-2004 efficiency.

This condition can occur because of changes in efficiency is strong in 2000-2004 associated with the ongoing consolidation after the financial crisis of 1998 aggravated domestic political conditions affecting the investment climate, making it difficult to increase investor confidence shown by the low growth and low investment realization investation. Slowing changes in technical efficiency means a decline in the production frontier, because of declining production capability of the machine. One possible reason is the interference with the machine as well as the high price of new machinery because of the low value of the rupiah against the dollar. The same results with a research report Bappenas (2010).

In the period 2005-2007, the average efficiency of 89.7 percent CRS models, meaning that there is still potential to improve efficiency by optimizing the use of inputs in the industry amounted to 10.3 percent, assuming all companies operating at an optimal scale. VRS model of efficiency average of 97.06 percent, meaning that there is still potential to improve efficiency by optimizing the use of inputs by 2.94 percent, assuming the company is not operating at optimal scale due to factors constraints. Overall the 2005-2007 period were on a scale of inefficiency due to efficiencies of scale value by an average of 92.42 percent, still below 100 percent. Conditions return to scale is at $\lambda>1$ means that the degree of change in output as a result of changes in input called the degree of acquisition ascending (increasing returns to scale). In the period 2005-2007 the economy recovers. Meat processing industr efficiency showed a positive trend compared to the previous period despite higher interest rates and the exchange rate lower as well as access to financial resources is still low. Companies improve practices to optimize the use of technology and the value of managerial professionals to improve efficiency. These results are consistent with the findings of Setiawan (2013) and the National Development Planning Agency (2010). The company increased the efficiency of input use between, improve the layout of the production to shorten the switching between work stations, align the workflow in the workplace. Increased capital input engine and building a positive effect on the efficiency and productivity of the industry in this period.

In the period 2008-2010 the average efficiency of 90.52 percent CRS models, meaning that there is still potential to improve efficiency by optimizing the use of inputs in the industry amounted to 9.48 percent with the assumption that all companies operating at an optimal scale. VRS model of efficiency average of 96.21 percent, meaning that there is still potential to improve efficiency by optimizing the use of inputs by 3.75 per cent, assuming the company is not operating at optimal scale due to factors constraints.

Overall the 2008-2010 period were on a scale of inefficiency due to efficiencies of scale value by an average of 94.09 percent, still below 100 percent. Toscaleberada return 
conditions at $\lambda>1$ means that the degree of change in output as a result of changes in input called the degree of acquisition ascending (increasing returns to scale) .In general, the industry is on the condition of increasing returns to scale (IRS), means it is still possible for the company to improve more technical efficiency by reducing the level of technical inefficiency in the use of input and take advantage of economies of scale.

In 2008 the global financial crisis which affects the overall economy is no exception processing and preserving meat industry which affect the cost of raw materials and capital goods. In addition to the result of the global financial crisis of 2008, also the impact of the application of the Regulation of the Minister of Agriculture No. 59 / Permentan / HK.060 / $8 / 2007$ about the decline of the import quota beef up toward 10 percent. Rising prices of imported raw materials influence the decrease in efficiency (model VRS).

The results were the same as the Surjaningsih and Permono (2014), BPS (2015) and Sharif (2013) reported a decrease in the efficiency of the period 2008-2010 is the result of the increase of raw material usage and increase capital input. The condition occurs because of the increased consumption of raw materials and capital input will help drive production growth despite the global financial crisis. The industry is the only import-oriented so that by utilizing the domestic market alone is able to grow because only meet domestic needs.

In the period 2011-2013 the average efficiency of 85.29 percent CRS models, meaning that there is still potential to improve efficiency by optimizing the use of inputs in the industry amounted to 10.3 percent, assuming all companies operating at an optimal scale. VRS model of efficiency average of 92.61 percent, meaning that there is still potential to improve efficiency by optimizing the use of inputs by 2.94 percent, assuming the company is not operating at optimal scale due to factors constraints. Overall the 2011-2013 period were on a scale of inefficiency due to efficiencies of scale value by an average of 92.10 percent, still below 100 percent. Conditions return to scale is at $\lambda<1$, the degree of change in output as a result of changes in input called the degree of acquisition decreased (decreasing returns to scale).

This condition occurs when the increase in output was less than the increase in inputs. Decreasing returns to scale may occur due to increased scale of operations, but the company will occur experiencing processed meat products are also factors that can increase the productivity of the industry. On the side of the change in efficiency is seen that the company is still visible in the process of learning by doing in adopting technology that has not been able to operate in full capacity, in addition to the many problems the economy is fueling inflation and rupiah exchange rate so that will affect the efficiency in the selection of inputs sourced from imports.

In the 2011-2013 upheaval in both industrial raw materials availability issues and pricing issues. The decline in imports resulting decreased availability of raw materials and price increases helped to provide impact for the processing industry is mainly a problem of cost efficiency. The costs incurred for raw material usage resulting in reduced efficiency. These results are consistent with reports Aswicayono and Hill (2002).

\section{CONCLUSIONS}

Meat processing industry in Indonesia experienced a significant productivity growth over the last two decades, but the contribution of growth efficiency is still low. Measurement of the value of efficiency in this study is the value obtained from the technical efficiency estimated by the method of Data Envelopment Analysis -Variable Return to Scale (DEAVRS) input oriented. Based on estimates found that there are technical inefficiency average of 10.62 percent with a model of Constant Return to Scale (CRS) and 4.3 percent with a model of Variable Return to Scale (VRS). Scale efficiency average of 93.36 percent, meaning that there is still potential to increase the efficiency of scale in the meat processing industry amounted to 6.64 percent.

Inefficiency empirically analyzed by assuming that the industry is not operating at optimal scale in the production process due to factors existing constraints both micro- and macroeconomic. The analysis showed that the meat processing industry has been on a 
scale of inefficient primarily due to factors related to the input of raw materials, capital and energy use and labor. This indicates that there has been use of inputs that have not fit in the meat processing industry. In order to improve the efficiency of the industry, these results are useful for policy makers and meat processors to work optimally in determining the combination of input, to rationalize the process of acquiring the output of input use, as well as to design the right policy framework to address the problems identified in the sector meat processing. The results showed that the industry needs to modernize production systems to improve the capacity utilization of input factors, especially of raw materials, capital and energy. the need to develop the skills of workers in order to adapt to the use of technology. The raw material is the composition of the biggest costs arising in the production, which is around 80 percent of production costs, is primarily a meat raw materials and auxiliary materials. Governments can help in the method of obtaining the raw material meat by shortening the supply chain for the meat processing industry.

\section{REFERENCES}

1. Ali, Jabir. 'Productivity and Efficiency in Indian Meat Processing lindustri: A DEA Approach.' Indian Journal of Agricultural Economic, 2007. Vol 62(4) Pp. 637-648

2. Ali, J. and E. Pappa. "Understanding Structural Changes in Global Meat Sector: A Comparative Analysis Across Geographical Regions".Papers Presentation at21thAnnual IFAMA WorldForum and Symposium on the Road to 2050: Sustainabilityas a Business Opportunity, Frankfurt, Germany.June 20-23, 2011.

3. Aswicahyono, H. Total Factor Productivity in Indonesian Manufacturing, 1975-1993. PhD Thesis. Australian National University. Unpublished. 1998.

4. Badan Pusat Statistik. Statistik Industri Besar dan Sedang Indonesia 2013. BPS, Jakarta, Indonesia, 2015

5. Banker, Charnes, Cooper. 'Some Models For Estimating Technical And Scale Inefficiencies In DataEnvelopment Analysis.' Management Science Journal, 1984. Vol 30 (9), pp.1078-1092.

6. BAPPENAS. "Perubahan Produktivitas Industri Manufaktur Indonesia dan Faktor-Faktor yang Mempengaruhinya: Analisis Panel Data 2000-2007". Laporan Akhir. Direktorat Evaluasi Kinerja Pembangunan Sektoral Kementerian PPN/Bappenas. Jakarta. 2010.

7. Basri, M. C. The Political Economy of Manufacturing Protection in Indonesia 1975-1995 PhD Thesis. Australian National University. (Unpublished)., 2001.

8. Cesaro L., S. Marongiu., F. Arfini., M. Donati and M. G. Capelli. 'Methodology for Analysing Competitiveness, Efficiency and Economy of Scale. Use and Applications of DEA.' Working PaperFACEPA Deliverable No. D5.1.3, 2009.

9. Charnes, Cooper, Rhodes. 'Measuring the efficiency of decision making units.' European Journalof Operational Research, 1978. Vol. 2, Pp. 429-444.

10. Coelli, T., Rao, D., O"Donnell, C. and Battese, G. An Introduction to Efficiency and Productivity Analysis. Springer, New York, second edition. 2005.

11. Farrell, M. J.. 'The measurement of productive efficiency'. Journal of the Royal Statistical Society,, 1957. Vol 120, Pp. 252-90.

12. Giufrida, A. \& H. Gravelle. Measuring performance in primary care: Econometric analysis and DEA. Heslington York: Department of Economics and Related Studies University of York. 2001

13. Goncharuk G,A. 'How to make meat business moreEffective: A case of Ukraine.' British Food Journal, 2009. Vol. 111 No. 6,pp. 583-597

14. Gopinath, M., D. Pick and Y. Li. "Does Industrial Concentration Raise Productivity in Food Industries?". WorkingPaper. Annual Meeting of the Western Agricultural Economics Association. Long Beach, California July 28-31, 2002.

15. Keramidou I., A.Mimis and E.Pappa. 'Determinants of Efficiency of Prepared Meat Products lindustri in Greece'. European Journal of Social Sciences -, 2010. Volume 17, Number 4 Pp.509-520. 
16. Keramidou I., A.Mimis and E. Pappa. "Identifying efficiency drivers in the greek sausage industri: adouble bootstrap DEA approach." Economics Bulletin, 2011a. Vol. 31 no.1 pp. 442-452.

17. Keramidou I., A.Mimis, E.Pappa, and S. Filios. 'Efficiency of Meat Products lindustri in Greece: A Bootstrap DEA Approach'. International Journal of Interdisciplinary Social Sciences, 2011b. Volume 5, Issue 9, pp.15-28.

18. Keramidou, I. and A. Mimis. 'An Application of the Double-Bootstrap Data Envelopment Analysis to Investigate Sources of Efficiency in the Greek Poultry Sector'. World's Poultry Science Journal, 2011c.Vol. 67, Pp. 675-686.

19. Knudson,W.A., S. Miller and H. C.Peterson. "The Economic Impact Of The Michigan Food Processing Industries.The Strategic Marketing Institute". WorkingPaper 010910.Bussiness Innovation In Agriculture, Food And Natural Resources .Agriculture Hall, Michigan State University, East Lansing, 2010.

20. Kopelko M, Alfons Oude Lansink, Spiro Stefanou. "Analysis of static and dynamic productivity growth in the Spanish meat processing iindustri". Paper on European Association of Agricultural Economists 131st Seminar, September 18-19, 2012. Prague, Czech Republic

21. Kuncoro, Mudrajad. Ekonomika industri Indonesia:Menuju negara industri baru 2030. Penerbit Andi, Yogyakarta. 2007.

22. Kuncoro, Mudrajad. Metode Riset Untuk Bisnis dan Ekonomi. Bagaimana Meneliti dan Menulis Tesis?. Edisi 3. Penerbit Erlangga. Jakarta. 2009.

23. Margono, H. and S. C. Sharma. 'Technical Efficiency and Productivity Analysis in Indonesian Provincial Economies'. Discussion Papers Department of Economics Southern Illinois University Carbondale. 2004.

24. Margono, H. \& Sharma, S.C. 'Efficiency and Productivity Analyses of Indonesian Manufacturing Industries'. Journal of Asian Economics, 2006.17, Pp.979-995.

25. Modjo, Ikhsan., 2007."Total Factor Productivity in Indonesian Manufacturing: A Stochastic Frontier Approach", Global Economic Review. Vol. 36, No. 4, pp. 321-342.

26. Nossal, K, Sheng Y, and Zhao, S.. 'Productivity in the beef cattle andslaughter lamb industries. Meat and LivestockAustralia'.research report 08.13Australian Bureau of Agricultural and Resource Economics (ABARE). Australia. 2008.

27. Nurdianto, D.A.. 'Analisis Kolusi Industri Manufaktur Indonesia Tahun 1993-2000'. Jurnal Ekonomi dan Pembangunan Indonesia. 2004. No. 1, Vol. 4, Hal. 15-44.

28. Prabowo, H. E.T., dan E, Cabanda. "Stochastic Frontier Analysis of Indonesian Firm Efficiency: A Note", International Journal of Banking and Finance, 2011.Volume 8; Iss. 2, Article 5.

29. Priyanto, D., 2005. Beef Import Policy Evaluation Through Supply and Demand Analysis. National Seminar on Animal Husbandry and Veterinary Technology, 2005. Livestock Development Center and other research. P. 275-284.

30. Seiford, L. M. and R. M. Thrall. 'Recent developments in DEA: the mathematical programming approach to frontier analysis'. Journal of Econometrics, 1990. 46, 7-38.

31. Sengupta J.K.. 'Data Envelopment Analysis for Efficiency Measurement in the Stochastic Case'. Computer and Operations Research. 1987.1: 117-129.

32. Sengupta, J.R.. Dynamics of Data Envelopment Analysis: Theory of Systems Efficiency. 1995. pp: 70-73. Kluwer Academic Publishers, Boston.

33. Surjaningsih, N. and B. P. Permono. The Dynamics of Total Factor Productivity of Medium and Large Manufacturing in Indonesia.Bulletin of Monetary, Economics and Banking, 2014. Pp. 278-308.

34. Syarif, Haniwar, 2013. "Opportunity in indonesian meat intermediate industry". Papers National Assocoation Meat Processor Association. Brisbane. 22-23 Agustus 2013

35. Varian H. R. Intermediate Microeconomics "A Modern Approach". Eighth Edition. W. W. Norton \& Company.New York.London. 2010.

36. Waldman, D.E. and E.J. Jensen. Industrial Organization: Theory and Practice. Addison Wesley Educational Publishers Inc. United States of America. 1998. 
37. Ward, C.E. "Productivity - Concentration Relationship in the U.S. Meatpacking lindustri." Southern Journal of Agricultural Economics. 1988.19. Pp. 217-222.

38. Widiati R. dan M. Kuncoro, 2006. Industri Testil Dan Produk Tekstil Di Indonesia, Tahun 1996 Dan 2001: Pendekatan Kluster dan SCP = Textile and Apparel Industries in Indonesia, 1996 and 2001: Cluster and SCP Approach. Sosiosains XIX(1). Pp. 59-76

39. World Bank..Report No. 9350-IND, The World Bank, Washington, D. C. 1991.

40. Xia, $Y$ andS. Buccola. 'Size, cost, and productivity in the meat processing industries'. Journal of Agribusiness 2002.Vol 18.3 Pp: 283-299.

41. Xie, X. and D. J. Cummins. 'Efficiency, productivity, and scale economies in the U.S. property-liability insurance industri'. Journal of Productivity Analysis, 2012.Volume 39, Issue 2, Pp. 141-164.

42. Yahmed, S. Ben and D. Sean. Impor Competition, Domestic Regulasi and Firm-Level Productivity Growth in OECD. OECD Economic Departement Working Papers 980. Sept 3, 2012. 